\title{
AC 2010-1434: INSPIRING MINORITIES TO ENTER THE STEM PIPELINE THROUGH NSBE JR.
}

\section{Jamila Cola, Georgia Institute of Technology}

Dr. Jamila Cola is a program director at the Center for Education Integrating Science, Mathematics, and Computing (CEISMC) at the Georgia Institute of Technology. She recieved her $\mathrm{Ph} . \mathrm{D}$. in physical chemistry from Purdue University. Her current interests are minority student achievment in K-12 STEM subjects.

\section{Douglas Edwards, Westlake High School}

Mr. Douglas Edwards is the Math/Science Magnet Coordinator at Westlake High School. He received his bachelor of science in electrical engineering from the University of Dayton and has a master's degree from Georgia State University. Douglas serves as the faculty sponsor of the Westlake NSBE Jr. and Engineers Without Borders chapters.

\section{Margaret Tarver, Tri-Cities High School}

Mrs. Margaret Tarver is a chemistry teacher, graduation coach, and NSBE Jr. sponsor at Tri-Cities High School. She received her B.S. in chemistry from Alabama A\&M, and her Masters in science education from Georgia State University. She received the Golden Torch Award--PCI Director of the Year from the National Society of Black Engineers in 2010 for her work with the Tri-Cities High School NSBE Jr. chapter.

\section{Donna Llewellyn, Georgia Institute of Technology}

Dr. Donna C. Llewellyn is the Director of the Center for the Enhancement of Teaching and Learning (CETL) and an adjunct associate professor in Industrial and Systems Engineering at the Georgia Institute of Technology. Her current areas of research are in equity of engineering education and assessment of instruction. Donna is the PI of the STEP program.

\section{Marion Usselman, Georgia Institute of Technology}

Dr. Marion C. Usselman is Associate Director for Academic Outreach at the Center for Education Integrating Science, Mathematics and Computing (CEISMC) at the Georgia Institute of Technology. Marion received her Ph.D. in biophysics from Johns Hopkins University and taught biology at the University of North Carolina, Charlotte. She focuses on equity and access issues in education and K-12 educational reform. She is the co-PI of the STEP program. 


\title{
Inspiring Minorities to Enter the STEM Pipeline Through NSBE Jr.
}

\begin{abstract}
The National Society of Black Engineers (NSBE) is the largest student managed organization in the United States. It was founded in 1975 and now serves over 10,000 collegiate members at over 300 colleges and universities across the country. NSBE's mission is to increase the number of culturally responsible black engineers who excel academically, succeed professionally, and positively impact the community. NSBE also has a large professional membership of approximately 3000 alumni members and a significant pre-college membership that ranges from grade seven to grade twelve. The goal of these NSBE Jr. chapters is to inspire young minds to pursue science, technology, engineering or math (STEM) as fields of study when entering college. With its Pre-College Initiative (PCI) program, NSBE aims to aid the entire engineering pipeline by preparing highly motivated and skilled high school students for the rigors of a university-level math, science, and engineering curriculum.
\end{abstract}

As part of an NSF GK-12 program, the Georgia Institute of Technology implemented NSBE Jr. chapters at two high schools in metro Atlanta, both with under-represented minority enrollments of over 95\%. One is a Math and Science Magnet school, and the other is a Performing Arts Magnet school. Both NSBE Jr. chapters have now been in existence for at least five years, and have flourished with leadership by Georgia Tech graduate students. This paper will describe the activities implemented at these two different types of schools and will track the NSBE Jr. membership over time. This tracking includes reporting on which majors the NSBE Jr. students chose when entering college, and hence whether the two chapter have met NSBE's goal of helping to inspire students to enter STEM fields.

\section{Introduction}

Globalization has challenged the preeminence and competitiveness of the United States in science and technology according to the 2007 National Academies Report, Rising Above the Gathering Storm: Energizing America for a Brighter Economic Future. ${ }^{1}$ As noted by the Commission on the Advancement of Women and Minorities in Science, Engineering and Technology Development, investing in a diverse scientific workforce will lead to innovation and creativity that will sharpen the competitive edge of the United States. ${ }^{2}$ The projected US population trends illustrate an increase in minority population from $30.6 \%$ in 2000 to $46.3 \%$ in $2040 .^{3}$ In the state of Georgia, minorities already make up 54\% of the total K-12 student enrollment. ${ }^{4}$ Therefore, in order for the United States in general, and Georgia specifically, to remain competitive and to utilize all of its intellectual capital, we will need to cultivate the untapped STEM talents of underrepresented minorities. Introducing underrepresented minorities to the STEM pipeline is the first step towards engaging them in the science, engineering, and technology enterprise. Despite several barriers preventing minorities from entering and remaining in STEM fields, there are many best practices to encourage and inspire minorities to contribute to STEM careers. 
In 2007, African Americans were granted 8.6\% of all science and engineering baccalaureate degrees. ${ }^{5}$ Although many programs have been created and developed over the years to support talented minority students, underrepresentation of minorities within STEM majors and graduate programs, as well as in the STEM workforce, still persists. Previous research shows that a supplemental informal approach to nurturing STEM education and introducing STEM careers can be effective at reaching underserved secondary students. ${ }^{6}$ Quality out-of-school programs that are social and academic also play an important role in increasing student achievement and providing a supportive environment. ${ }^{7,8}$ As part of an effort to inspire more African American high school students to major in STEM fields, graduate students participating in Georgia Tech's NSF GK-12 Program collaborated with high school administrators and teachers to form precollege chapters of NSBE at two schools in a heavily African American area of south Fulton County. As discussed in this paper, evidence suggests that NSBE Jr. activities, complemented by Advanced Placement (AP) mathematics and science courses, can give students the confidence, peer support, and feeling of working towards societal benefit that may lead to commitment to a STEM major in college.

\section{The National Society of Black Engineers}

NSBE is an organization dedicated to supporting and maintaining the pipeline of black engineers. NSBE was founded by 6 engineering students at Purdue University with a goal to recruit and retain graduate students in engineering and has since grown to 223 chapters on college and university campuses, 65 Alumni Extension chapters for professional engineers and 89 pre-college chapters for high school students." The stated mission of NSBE is "to increase the number of culturally responsible black engineers who excel academically, succeed professionally, and positively impact the community."

The following objectives of NSBE were established to meet the mission of the Society:

- Stimulate and develop student interests in the various engineering disciplines

- Strive to increase the number of minority students studying engineering at both the undergraduate and graduate levels

- Encourage members to seek advanced degrees in engineering or related fields and to obtain professional engineering registrations

- Promote public awareness of engineering and opportunities for blacks and other minorities in that profession

- Function as a representative body on issues and developments that affect the careers of black engineers

The NSBE Pre-College Initiative (PCI) Program is designed to stimulate interest in STEM fields and encourage students in grades K-12 to attend college and pursue STEM degrees. ${ }^{9}$ STEM precollege programs and early introduction to STEM careers are known factors that facilitate the progression of minorities into STEM majors. ${ }^{10}$ NSBE Jr. members can form chapters in their schools, churches or community organization. Advisors of NSBE Jr. support and assist chapters to implement various projects and activities. They can be NSBE collegiate or Alumni Extension members, parents/guardians, teachers, counselors or school administrators. The NSBE PCI Program provides NSBE Jr. members in grades 6-12 with resources such as financial aid information, career counseling guides, guides on how to develop a chapter, and SAT/ACT 
preparation materials. NSBE also offers scholarships, awards, and competitions for NSBE Jr. Members such as Try-Math-A-Lon, Science Fair, and the Golden Torch Awards. Many NSBE Jr. members attend the national PCI Mini-Conference held at the NSBE National Convention. The national convention and regional conferences promote academic and technical development and provide an opportunity to meet other NSBE Jr. members from around the world.

NSBE PCI Objectives are:

- To help students have positive attitudes toward academic excellence

- To stimulate enthusiasm about science, technology, engineering, and mathematics

- To encourage K-12 students to purse degrees in engineering and other technical fields

- To increase the number of African Americans attending and graduating from college

- To encourage and support parental commitment to children's education

- To raise cultural awareness among students

Nationally, PCI K-12 programs provide opportunities for academic excellence, scholarships, leadership training, professional development, and insight into career opportunities. Successful completion of NSBE Jr. high school activities and competitions may increase the self-confidence and self-efficacy for young African American males, which are important factors in their consideration of a STEM career. ${ }^{11}$ Leslie found that $43 \%$ of white men perceived their math and science preparation to be better than most, while $26 \%$ of black men and $16 \%$ of black women shared the same perception of themselves. ${ }^{12}$ However, experiences enabled by NSBE Jr. such as winning a math and science competition or placing in the NSBE science fair can lead to a positive self perception of being prepared in math and science. Additionally, attendance at a NSBE national convention can alter a students' self-concept because they will see and meet many other African American male and female engineering professionals and begin to see themselves as a future engineer. NSBE Jr. creates a peer group of African American youth at local high schools who value academic excellence and encourage each other to excel in advanced math and science courses. Establishing peer groups for African American students is necessary

in order to increase the number of students who have academic success, ${ }^{13}$ positive self perception, and self-efficacy, and a strong interest in STEM careers.

\section{Instituting NSBE Jr. Chapters at Local High Schools}

\section{Georgia Tech Partnerships with Local High Schools}

The Center for Education Integrating Science, Mathematics, and Computing (CEISMC) and the Center for Teaching and Learning (CETL) at Georgia Tech collaborate on an NSF GK-12 program entitled the Student and Teacher Enhancement Partnership (STEP) program which places 12 graduate students per year in 6 Atlanta area high schools. Since 2001, each year two STEP graduate Fellows have been assigned to each school and tasked with creating a team with a teacher STEP coordinator and other teachers at the school. The team then decides upon a plan of action for that year that meets the needs of the school and utilizes the expertise and interest of the Fellow. In prior years the STEP Fellows spent an average of 15 hours per week at their assigned school, but the program now requires a reduced commitment of 7 hours per week. The goals of the STEP program are to broaden the education of STEM graduate students through exposure to intensive experiences in educational pedagogy, assist K-12 teachers in improving K-12 student learning, and developing extended partnerships between Georgia Tech and the STEP schools. 
STEP teams at two primarily African American Atlanta-area high schools, Tri-Cities High School and Westlake High School, decided to create pre-college NSBE chapters to:

- Introduce students to engineering careers

- Create opportunities to show how engineers contribute to society and their community

- Foster peer support for academic excellence

- Expose minorities to a network of other black engineers by attending NSBE regional and national conferences

- Inspire students to pursue STEM majors and contribute to the STEM workforce

\section{Tri-Cities High School}

Tri-Cities High School (TCHS) was established in 1988 in Fulton County, Georgia. The Visual and Performing Arts Magnet Program at Tri-Cities High School (TCHS) was launched in 1990 to provide students with specialized training in the arts while earning a high school diploma. TCHS has an enrollment of 1869 , with $74 \%$ listed as economically disadvantaged. The demographics of the school are: $81 \%$ African American, 13\% Hispanic, 2\% Asian, 2\% White, and $2 \%$ multicultural. TCHS offers specialty classes in performing arts; they also offer AP classes in Chemistry, Physics, Calculus, and Biology.

The STEP Fellow at TCHS in 2004 developed hands-on activities and projects to illustrate the various engineering disciplines and worked to form a pre-college NSBE chapter. From 20042009, 53 students have participated in NSBE Jr. Its student membership has been $74 \%$ African American, 17\% Asian, and 9\% White. Over half of the NSBE Jr. high school students attended regional and national NSBE conferences.

At TCHS NSBE Jr. students participated in the math and science quiz bowl, rocket building workshops, and college tours. NSBE Jr. meetings were held after school for an hour to conduct business and participate in hands-on activities and a public speaking seminar. Each meeting began with a review of an SAT math question, which encouraged students to develop more positive attitudes about the college entrance exam and practice math concepts. A seminar on requirements of admission into engineering programs, campus tours, and presentations by graduate students, were all coordinated by the STEP Fellow. TCHS has also been involved with NSBE Jr. competitions including: Robotics, math, engineering design where activities have included building a hover craft, building Lego robots, bridge building, making ice cream, building different rockets, and building cars, all which promoted teamwork, and development of basic physics, chemical and environmental concepts. In 2009, TCHS participated in a roller coaster competition, Junior Engineering Technical Society (JETS) competition, and made biodiesel fuel, with hopes of collaborating with another high school to build a go-kart and test the fuel.

Over the past six years, 39 African American students have been involved with NSBE Jr. at TCHS. Figure 1 shows the annual distribution of declared majors for African American NSBE Jr. students at TCHS. Sixteen of those African American students from TCHS have chosen to purse STEM majors in college. Ten students chose science majors and six chose to major in engineering. Half of the science majors chose biology (5) and the other half chose chemistry (2), computer science (1), Pre-med. (1) and mathematics (1). The engineering majors spread across 
computer, aerospace, agricultural, biomedical, and mechanical engineering disciplines. Thirteen of the NSBE Jr. members that chose science and engineering fields were female.

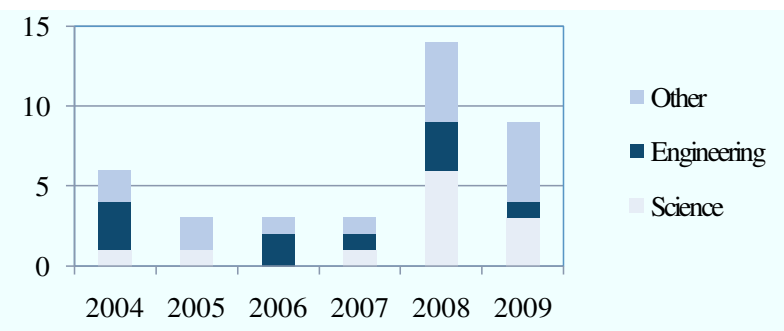

Figure 1. TCHS NSBE Jr. Chapter- Annual distribution of African Americans students' intended major in college

All three males chose engineering fields. Figure 2 illustrates the demographic distribution of NSBE Jr. members and the discipline they decided to pursue in college. The Asian Americans involved in NSBE Jr. did not pursue science, only engineering, and non-STEM fields. In the Hispanic group, the STEM fields pursued were biology (2) and computer engineering (1). It is likely that the NSBE chapter at TCHS performing arts magnet school was able to inspire 22-42\% of its members to enroll at four-year universities as science and engineering majors. Although most of the NSBE Jr. participants reported which university or college they attended and their chosen major, no information was received for 17\% of the NSBE membership from 2004-2009. The NSBE Jr. members without information on their intended major or college were discarded in this study, so the data reflects the NSBE Jr. students who provided information on their intended major and university.

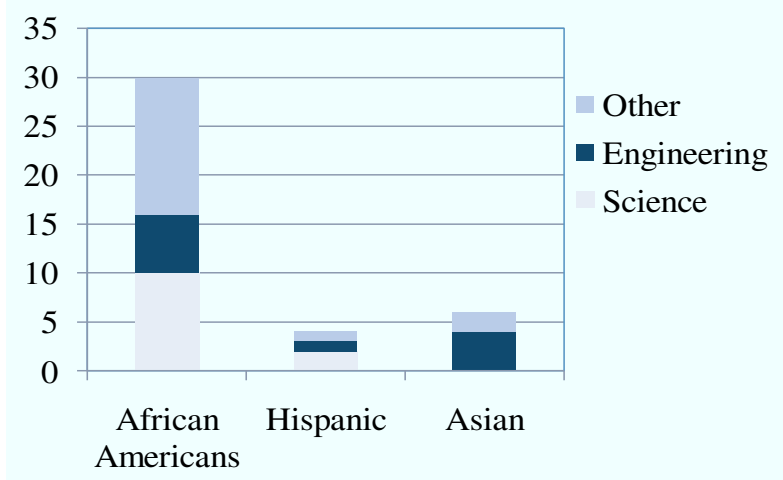

Figure 2. TCHS NSBE Jr. Chapter- Demographic distribution of students' intended major in college 


\section{Westlake High School}

Westlake High School (WHS) is located in a middle socio-economic and primarily African American area of southwest Atlanta, Georgia in Fulton County. The high school was formed in the fall of 1988 by the consolidation of Westwood High School and Lakeshore High School, and in 2009 enrolled 2,357 students; 98\% were African American, 1\% Asian, 1\% multicultural and $48 \%$ were eligible for free/reduced meals. The Georgia Department of Education and also the Southeastern Association of Colleges and Schools accredited WHS as the magnet school for math and science for South Fulton County in 1999. After the 2008-2009 school year, 87\% of the students went on to some kind of post-secondary education.

WHS's Math/Science Magnet Program prepares students for the academic and career fields of math, science, engineering, and technology through rigorous instruction, relevant experiences and supportive relationships. Students must complete twelve credit hours of math and science courses approved by the magnet program coordinator in order to receive a magnet seal on their diploma. The freshmen and sophomore year requires honors courses in biology, geometry, algebra II, and chemistry, and during these two years students also take a research methods course that requires them to develop a research paper that is submitted to the school science fair. During the sophomore year, students take a math technology course that incorporates statistical analysis, enabling the students to perform hypothesis testing as part of their science fair topic. During their junior and senior year students choose a course of study focused around medical science, engineering, or digital media/computer science. Students in the medical science program of study take courses that include human anatomy, genetics, microbiology, honors pre-calculus, AP chemistry and AP biology. Students in the engineering program of study take preengineering concepts, introduction to drafting, introduction to engineering, honors pre-calculus, AP calculus, and AP Physics. Students in the computer science program of study take web design, digital media concepts, beginning programming, honors pre-calculus, and AP computer science. Georgia Tech STEP Fellows have assisted and sometimes instructed in many of these courses ranging from honors geometry to AP Physics.

Typically, during their sophomore to senior year, students engage in extracurricular clubs including but not limited to Medical Sciences Club, Math Team, NSBE Jr., Engineers Without Borders (EWB), Robotics Team, or Digital Design Club. Georgia Tech STEP Fellows often assist with these clubs by providing instruction, conducting activities, and coordinating field trips. Magnet students compete as part of these clubs and have won the NSBE regional and national Try-Math-A-lon competitions and received the Georgia Tech Educational Partnership Award and EWB Pre-College Chapter Award. Also, some students participate in summer research internships at Georgia Tech for five weeks through the Center for Education Integrating Science, Mathematics, and Computing (CEISMC).

The NSBE Jr. chapter at WHS began in the fall of 2002 through the initiation and sponsorship of a Georgia Tech STEP Fellow. NSBE activities that occurred that year and every year since include the Georgia Tech PCI Visitation Day which focuses on providing information and inspiration on attending college, attending the NSBE fall regional conference, and attending the NSBE spring national conference. Every year students conduct fundraisers to reduce the cost of conference trips. At these conferences students participate in workshops and compete in the 
NSBE Jr. Try-Math-Alon, Engineering Design, and Science Fair competition. The Westlake NSBE Jr. chapter placed $1^{\text {st }}$ in the 2006-2008 Regional Try-Math-Alon and placed $1^{\text {st }}$ in the National Try-Math-Alon in 2008. Beginning in 2005 NSBE Jr. members began participating in the BEST Robotics competition and continue to participate each year. In 2005, students competed in the FIRST robotics competition.

In the fall of 2006, a Georgia Tech STEP Fellow worked with the NSBE Jr. chapter to initiate the first high school chapter of Engineers Without Borders (EWB). Recent research shows that some minority students are interested in a career that serves society or the community. Understanding how engineers contribute to society helps stabilize students' commitment to the STEM field. ${ }^{14}$ Student involvement in EWB may have an impact on the persistence of students in science and engineering at WHS. Most of the high school students in NSBE Jr. were also members of EWB and seven of these students attended the EWB International Conference in 2007 where they presented on their solar powered vaccine refrigeration project and solar cooker project. Former STEP Fellows helped raise funds for the students and sponsors to travel to Arusha, Tanzania in the summer of 2007 to implement their solar cooker project.

NSBE Jr./EWB (students pay one price to be members of both organizations) at WHS meets weekly to organize and prepare for competitions and attend conferences. Their executive board goes through two workshops with the sponsor on collective leadership so that the students are clear on leadership roles and responsibilities and meet bi-monthly to prepare for meetings and debrief previous meetings and activities. In addition, the executive board shares information with the general body on community service events. Also, senior level students offer tutoring to junior level students during general body meetings, which generally occur during students' one hour lunch period. Meetings begin with stating the NSBE mission and general announcements. Students then break into project or competition groups. Current projects include converting a gasoline powered go-kart to run on biodiesel and solar powering the laptop computer lab of the United African Alliance Community Center (UAACC) in Arusha, Tanzania. Beginning in 2007 NSBE Jr. members began organizing and conducting workshops to assist in the institution of the JETS chapter of WHS's feeder school, Sandtown Middle School. The two schools have continued to work together and were recognized by the Fulton County Commission through a Proclamation in November 2008.

One hundred percent of students from the Magnet Program attend a variety of colleges and universities including Clemson University, Georgetown University, Georgia Institute of Technology, Harvard University, Morehouse College, North Carolina Agricultural and Technical State University, Princeton University, Spelman College, University of Georgia, Xavier University of Louisiana, and Yale University. On average, 99\% of the magnet students have been eligible for the Georgia's HOPE scholarship, awarded to students who maintain a B average in high school, and $63 \%$ of the magnet students have received scholarships other than HOPE for the years 2005-2009. 


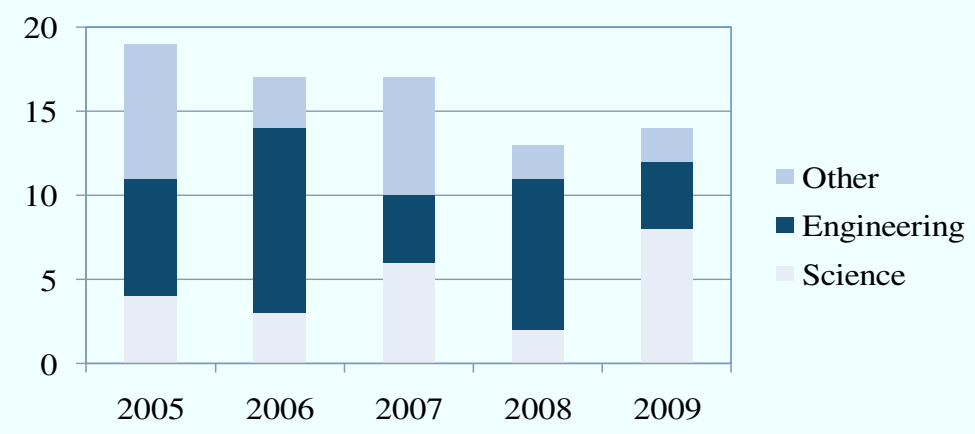

Figure 3. WHS NSBE Jr. Chapter- Annual distribution of students' intended major in college

The annual distribution of declared college majors for NSBE Jr. for WHS is shown in Figure 3. Westlake adds a minimum of at least 10 students to the STEM pipeline each year, although the distributions of science and engineering majors fluctuates. There are some noticeable trends in the intended majors as well as colleges and universities chosen by WHS students. A surprising data fact was the gender distribution among those who chose engineering fields. At WHS, African American women (17) were just as likely as African American men (18) to pursue engineering degrees. Nine men with intentions to major in engineering chose to attend Historically Black Colleges and Universities (HBCUs), whereas six women interested in engineering chose to attend a HBCU. The women intending to major in engineering attended HBCUs (6), universities within Georgia (4), and other Research Intensive institutions outside of Georgia. Of the thirteen men interested in science their intended majors were: computer science (6), biology (3), math (1), and atmospheric science (1). Only two of the men interested in science went to HBCUs (in math and biology). Five of the nine women in science chose to attend an HBCU: chemistry (1), math (2), and biology (2). The other women attended Research Intensive universities in Georgia. While there is a clear presence of women interested in engineering at WHS, this is not aligned with previous data. ${ }^{5}$ Also, $39 \%$ of the WHS students intended to go to various HBCUs while $24 \%$ chose to attend Georgia Tech. Since HBCUs are the leading institutions awarding bachelor degrees to underrepresented minorities in science and engineering ${ }^{5}$, this is expected. Georgia State University is the second in this regard. According to Diverse: Issues in Higher Education, Georgia Institute of Technology was ranked \#1 in engineering bachelor's degrees awarded to African American students in 2009. ${ }^{15}$ The NSBE Jr. chapter at WHS may have been an important factor in encouraging 65-85\% of its membership to enroll into four year universities as STEM majors.

From 2004-2009, over 43\% of the African American students in NSBE Jr. chapters from both Tri-Cities and Westlake high school chose to go to in-state schools as shown in Figure 4. The students chose to attend the following schools in Georgia: Georgia Tech, University of Georgia (UGA), Georgia State University (GSU), Albany State, Southern Polytechnic State University (SPSU), and West Georgia. Most of these students attended Georgia Tech (20\%) or the 
University of Georgia (9\%) to pursue science or engineering bachelor degrees. 35\% of African American students chose to attend an HBCU to pursue their STEM studies, while $22 \%$ chose to study their intended STEM major at a university outside of their home state.

\title{
2004-2009 NSBE Jr. College Enrollment
}

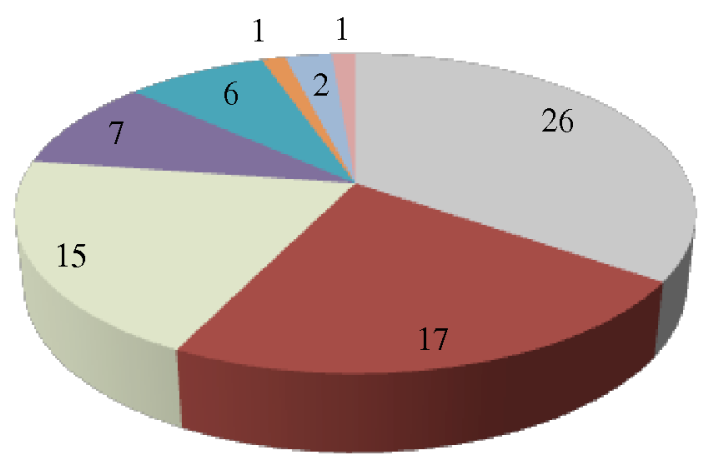

\author{
$\square$ HBCUs \\ - Out of State \\ Georgia Tech \\ - UGA \\ GSU \\ Albany State \\ - SPSU \\ West Georgia
}

Figure 4. Universities and Colleges Attended by NSBE Jr. Alumni at Westlake High School and Tri-Cities High School from 2004-2009

\section{Summary}

Two NSBE Jr. chapters in metro Atlanta produced 75 students over a five year period who intended to pursue a STEM degree in college. Given the low numbers of African American STEM majors, this number is noteworthy. It suggests that taking advanced science and math classes and being involved with NSBE Jr. may lead to enhanced STEM ability, positive selfesteem, and the confidence to choose a rigorous academic path in science and engineering. Partnerships between Georgia Tech and the high schools on a weekly basis have proven to be valuable. The high school teachers and students gain expanded access to Georgia Tech by fostering new relationships that lead to lab tours, student summer research experiences, seminars, and graduate student mentors. Students involved in NSBE Jr. are likely to pursue technical or scientific STEM careers given their exposure to advanced math and science classes and STEM activities, conferences, and competitions. The outcomes suggest that NSBE Jr. provides an academically supportive environment that many underrepresented minorities need to excel in the classroom and stimulate enthusiasm in STEM fields. 


\section{Bibliography}

1. National Adademy of Sciences, National Academy of Engineering, and Institute of Medicine of the National Academies. Committee on Science, Engineering, and Public Policy. (2007). Rising Above the Gathering Storm: Energizing and Employing America for a Brighter Economic Future. Washington, D.C.: The National Academies Press,

2. Commission on the advancement of Women and Minorities in Science, Engineering, and Technology. (2000). Land of plenty: Diversity as America's competitive edge in science, engineering, and technology. Arlington, VA: National Science Foundation.

3. U.S. Census Bureau, 2004, "U.S. Interim Projections by Age, Sex, Race, and Hispanic Origin," http://www.census.gov/ipc/www/usinterimproj/

4. Georgia Department of Education-http://www.doe.k12.ga.us

5. National Science Foundation, Division of Science Resources Statistics, Women, Minorities, and Persons with Disabilities in Science and Engineering: 2009, NSF 09-305 ( Arlington, VA; January 2009). Available from http://www.nsf.gov/statistics/wmpd/.

6. Jones, L.S. Science Education (1997) 81, 663.

7. Lauer,P.A., Akiba, M., Wilkerson, S.B., Apthrop, H.S., Snow, D., and Martin-Glenn, M. L. (2006) Review of Educational Research, 76, 275.

8. Zaff, J. F., Moor, K.A., Papillo, A.R., Williams (2003) S. Journal of Adolescent Research, 18, 599.

9. National Society of Black Engineers website: http://national.nsbe.org

10. George, Y.S., Neale, D.S., Horne, V.V., Malcom, S.M. (2001). In pursuit of a diverse science, technology, engineering, and mathematics workforce: Recommended research priorities to enhance participation by underrepresented minorities. Washington, DC: American Association for the Advancement of Science.

11. Post, P., Stewart, M. A., and Smith, P.L.(1991) Journal of Vocational Behavior, 38, 179.

12. L. L. Leslie, G.T. McClure, R.L. Oaxaca, Journal of Higher Education (1998) 69,3,239.

13. L. Steinberg, S.M. Dornbusch, and B.B. Brown, American Psychologist, (1992) 47, 6, 723.

14. J. Grandy, Journal of Higher Education (1998) 69, 6, 589.

15. Diverse Issues in Higher Education Top 100 Degree Producers 2009 website:

http://diverseeducation.com/top100/top100listing.html 